\title{
Mesenchymal stem cell surgery, rescue and regeneration in retinitis pigmentosa: clinical and rehabilitative prognostic aspects
}

\author{
Paolo Giuseppe Limoli ${ }^{\mathrm{a}, *}$, Celeste Silvana Serena Limoli ${ }^{\mathrm{a}}$, Marco Ulises Morales ${ }^{\mathrm{b}}$ \\ and Enzo Maria Vingoloc \\ ${ }^{a}$ Low Vision Research Centre of Milan, p.zza Sempione 3, Milan, Italy \\ ${ }^{\mathrm{b}}$ Division of Clinical Neurosciences, University of Nottingham, Queen's Medical Centre, Nottingham, United \\ Kingdom \\ ${ }^{\mathrm{c} D e p a r t m e n t ~ o f ~ S e n s e ~ O r g a n s, ~ F a c u l t y ~ o f ~ M e d i c i n e ~ a n d ~ O d o n t o l o g y, ~ S a p i e n z a ~ U n i v e r s i t y ~ o f ~ R o m e, ~ p . l e ~ A . ~ M o r o, ~}$ \\ Rome, Italy
}

\begin{abstract}
.
Purpose: To assess whether treatment with the Limoli Retinal Restoration Technique (LRRT) can be performed in patients with retinitis pigmentosa (RP), grafting the autologous cells in a deep scleral pocket above the choroid of each eye to exert their beneficial effect on the residual retinal cells.

Methods: The patients were subjected to a complete ophthalmological examination, including best corrected visual acuity (BCVA), close-up visus measurements, spectral domain-optical coherence tomography (SD-OCT), microperimetry (MY), and electroretinography (ERG). Furthermore, the complete ophthalmological examination was carried out at baseline (T0) and at 6 months (T180) after surgery. The Shapiro-Wilk test was used to assess the normality of distribution of the investigated parameters. A mixed linear regression model was used to analyse the difference in all the studied parameters at T0 and T180, and to compare the mean change between the two groups. All statistical analyses were performed with STATA 14.0 (Collage Station, Texas, USA).

Results: LRRT treatment was performed in 34 eyes of $25 \mathrm{RP}$ patients recruited for the study. The eyes were classified in two groups on the basis of foveal thickness (FT) assessed by SD-OCT: 14 eyes in Group A (FT $\leq 190 \mu \mathrm{m}$ ) and the remaining 20 ones in Group B (FT>190 $\mu \mathrm{m})$. Although it had not reached the statistical significance, Group B showed a better improvement in BCVA, residual close-up visus and sensitivity than Group A.

Conclusions: Previous studies have described the role of LRRT in slowing down retinal degenerative diseases. Consequently, this surgical procedure could improve the clinical and rehabilitative prognostic parameters in RP patients. On the other hand, further clinical research and studies with longer follow-up will be needed to evaluate its efficacy.
\end{abstract}

Keywords: Autograft, cell surgery, embryonic stem cells (ESC), foveal thickness, growth factor (GF), induced pluripotent stem cells (iPSCs), Limoli retinal restoration technique (LRRT), mesenchymal cell (MSC), retinitis pigmentosa (RP)

\footnotetext{
${ }^{*}$ Corresponding author: Paolo Giuseppe Limoli, Low Vision Research Centre of Milan, p.zza Sempione 3, 20145 Milan, Italy. Tel.: +39/3356021378; Fax: +39/3315865; E-mail: paololimoli@ libero.it.
}

\section{Introduction}

Retinitis pigmentosa (RP) is one of the most common retinal diseases and causes visual impairment and irreversible blindness, affecting 1.5 million people worldwide, with a prevalence estimated at 
1:4.000 (Pagon 1988; Hartong et al., 2006; Hamel 2006). The etiology of RP is genetic, caused by different types of gene mutation that explain the damage and resulting death of rod photoreceptors. Primary rod photoreceptor degeneration is later followed by secondary loss in cone photoreceptors. This sequence of events underlies the prevalent symptoms of RP: night blindness, tunnel vision, and, later on, progressive loss in central vision. The central retina, which mainly contains cones, is relatively unaffected until the late stage of the disease, even though alterations in foveal anatomy can arise in earlier stages. Degeneration affects cone photoreceptors in the macular area and consequently visual acuity can decrease to the point of developing complete blindness. Full-blown RP is defined by three main clinical signs: osteoclast pigmentation, rarefaction of retinal vessels, and pallor of the optic nerve head. Electroretinographic anomalies are identified even at an early stage of RP. As the pathology progresses, the amplitude of electroretinogram (ERG) recordings decreases and its latency time increases, affecting the scotopic components (rods) before the photopic ones (cones). Finally, ERG recording under scotopic and photopic conditions disappears. This manifestation is a well-established diagnostic feature of RP (McCulloch et al., 2015). Primary loss in rod photoreceptors is followed by cone photoreceptor degeneration and can be assessed by optical coherence tomography (OCT). The latter records a progressive reduction of the stromal thickness, which occurs initially at the periphery and then affects the whole retinal stroma, eventually leading to its atrophy (Fisher et al., 2008; Hood et al., 2009; Aizawa et al., 2009; Tamaki and Matsuo, 2011). A further study has shown that there is a positive linear correlation between the decrease in visual field sensitivity and the thinning of the outer segments (Liu et al., 2016). Therefore, in RP, retinal thinning secondary to cell loss is linked with impairment of visual acuity (Sandberg et al., 2005; Witkin et al., 2006).

The cause of RP is not soley explained by genetics, as there are other biological mechanisms involving, among others, cone photoreceptors, which are genetically unaffected. These mechanisms include: neurotrophism, apoptosis, vascular change, oxidation, inflammation or immunology (Campochiaro and Mir, 2018; Yi et al., 2018; Beutelspacher et al., 2011; Punzo et al., 2011; Langmann 2007, Pescosolido et al., 2014, Nebbioso et al., 2013). New therapeutic approaches to RP include restoring defective genes and stem cell transplantation to replace or repair defective or dead cells (Otani et al., 2004; Liang et al., 2001; Guadagni et al., 2015; Herse 2005; He et al., 2014; Tucker et al., 2014).

Gene therapy holds great potential, but it is currently at an experimental stage and has obtained only limited therapeutic results in vivo. Consequently, scientific interest is particularly directed at restoratory therapy based on stem cells. The latter aims to recover cell density as well as to preserve the remaining retinal cells by improving intra/extracellular conditions (Jones et al., 2017).

Stem cells are undifferentiated cells that have the ability to self-renew and differentiate into mature cells. This target can be reached by delivering embryonic stem cells (ESC), induced pluripotent stem cells (iPSC), or mesenchymal stem cells (MSC) into the eye in specific ways (Idelson et al., 2009; Klassen 2015; Takahashi and Yamanaka 2013; Ding et al., 2017). ESC, iPSC, and MSCs are characterized by self-renewal and multipotency, i.e., the ability to differentiate into the different cells of the three germ layers. The multipotency of MSC has been demonstrated in appropriate culture conditions with lineage-specific growth factors (GFs) that carry out the differentiation of MSCs into precise cell types (adipocytes, chondrocytes, and osteoblasts) (Romanov et al., 2005; Lindroos et al., 2010). Hence, MSCs play a fundamental role in organogenesis, remodeling and tissue repair (Baddour et al., 2012). Experimental studies have also described that MSCs may differentiate into retinal progenitor cells, photoreceptors, and retinal neurallike cells (Huo et al., 2010; Zarbin 2016). In addition, stem cells, particularly MSCs, can exert neuroprotective and pro-regenerative effects by secreting multiple paracrine factors (Moraes et al., 2012; Kyurkchiev et al., 2014; Johnson et al., 2014; Mead et al., 2014; Çerman et al., 2016). The adipose tissue is one of the most interesting collection sites of MSCs. Like bone marrow, the adipose tissue contains a large population of stem cells, usually called adipose-derived stem cells (ADSCs), within its stromal compartment. These cells are multipotent and can differentiate into various cell types: osteocytes, adipocytes, vascular endothelial cells, cardiomyocytes, pancreatic $\beta$-cells, and hepatocytes (Pittinger et al., 1999; Siniscalco et al., 2010; Rezeanejad et al., 2014; Emre et al., 2015; Hofer and Tuan, 2016).

ADSCs produce basic fibroblast growth factor (bFGF), vascular endothelial growth factor (VEGF), macrophage colony-stimulating factor (M-CSF), granulocyte-macrophage colony-stimulating factor 
(GM-CSF), placental growth factor (PlGF), transforming growth factor- $\beta$ (TGF $\beta$ ), hepatocyte growth factor (HGF), insulin-like growth factor-1 (IGF-1), interleukin (IL), angiogenin, ciliary neurotrophic factor (CNTF), and brain-derived neurotrophic factor (BDNF) (Lindroos et al., 2010; Mizuno, 2009; Luo et al., 2013). Another mesenchymal cell type that can be used for regenerative purposes is represented by adult adypocites. These can secrete specific hormones, called adipokines, which play a role in energy homeostasis. Fat cells produce epidermal growth factor (EGF), bFGF, IGF-1, IL, TGFß, pigmentepithelium-derived factor (PEDF), and adiponectin (Wang et al., 2008; Tilg and Moschen et al., 2006; Nakagami et al., 2006; Schaffler and Buchler, 2007).

Finally, platelets are another cell type of mesenchymal origin. Platelets are well known for their haemostatic action, but they can also release substances that promote tissue repair, angiogenesis, and modulation of inflammation (Jurk and Kehrel, 2005). Furthermore, they induce cell migration and adhesion at angiogenesis sites, as well as the dif- ferentiation of endothelial progenitors into mature endothelial cells (Mishra et al., 2011). Platelets produce platelet-derived growth factor (PDGF), IGF-1, TGF $\beta$, VEGF, bFGF, EGF, platelet-derived angiogenesis factor (PDAF), and thrombospondin (TSP) (Anitua et al., 2004; Qureshi et al., 2009; Antoniades and Williams, 1983).

Since the GFs secreted by MSCs in the retinal environment can be exploited to provide a therapeutic action, we consider the possibility of treating the retina affected by RP with a surgical technique called Limoli Retinal Restoration Technique (LRRT), described in previous works (Fig. 1) (Gentile et al., 2012; Limoli et al. 2014; Oner et al., 2019; Limoli et al. 2016; Limoli et al., 2017).

The aim of our research was to reduce or prevent the death of photoreceptors and consequently improve the clinical and rehabilitative prognostic aspects by means of LRRT surgery and to evaluate the improvement of visual function in RP patients. We postulated that the greater the residual number of retinal cells is, the greater the interaction between GFs

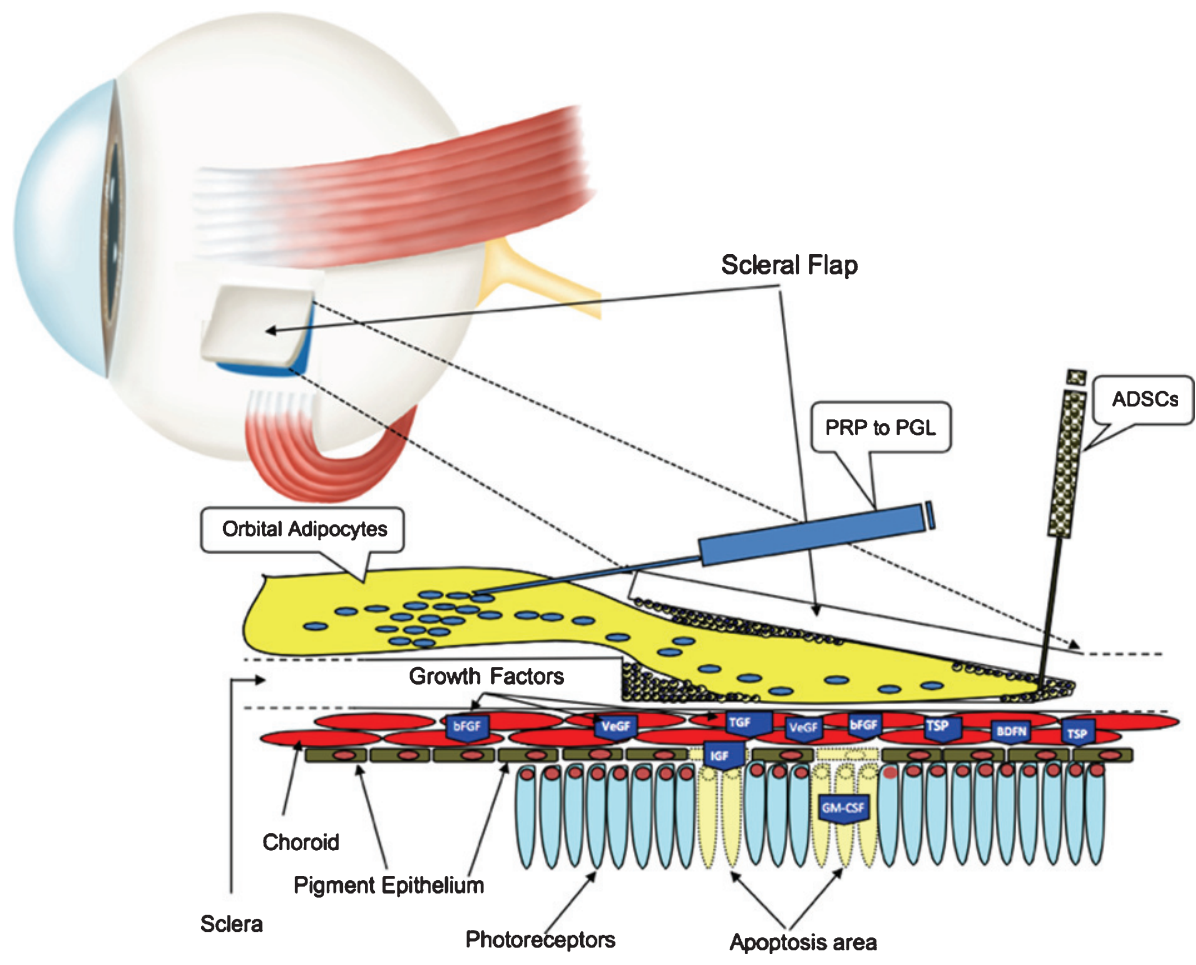

Fig. 1. The suprachoroidal autograft obtained by Limoli Retinal Restoration Technique (LRRT) allows placing fat stromal cells, adipose tissue-derived stem cells (ADSCs) and platelets (PLTs) obtained from PLT-rich plasma (PRP) close to the choroid. The production of growth factors (GF), characteristic of these cells, is poured directly into the choroidal flow, helping to maintain retinal cell trophism. The GFs, through the choroidal flow, have a direct action on the choroid, on the Müller cells, on the retinal pigment epithelium (RPE) cells with improvement of physiology of the outer segments (OS), on the rods and on the cones. 
and the membrane receptors of chorioretinal cells and therefore cellular activity and the improvement of visual performance (VP).

\section{Methods}

The study protocol was approved by the Institutional Review Board of the Low Vision Academy (No: 2016/A101, date: 1 October 2016) and, in accordance with the Helsinki Declaration, written consent was obtained from all the patients.

This retrospective clinical study included 34 eyes of 25 RP patients, 11 women and 14 men, with an average age of $45.9 \pm 18.36$ years (Table 1 ).

Patients who met the following criteria were eligible for the study:

- RP diagnosis by spectral domain-OCT (SDOCT), fundus autofluorescence imaging, and ERG analysis.

- Measurable visual acuity.

- Close-up visus between 7-64 pts, not evaluating very low ( $>64 \mathrm{pts})$ or non-incremental (6 pts) visus.

- Evaluation of a potential improvement with LRRT.

- Normal intraocular pressure.

- Any surgery performed for any ophthalmologic disease no earlier than 3 months before to ensure patient stability.

- Treatment and minimal risk of any potential harm from the procedure.

- 18 years of age or older.

- Medically stable condition.

Subjects who met any of the following criteria were excluded from participating in the study:

- Myopic spherical equivalent $>6$ diopters.

- Cataract, chorioretinal disorders, such as macular pucker with altered foveal area.

- Inability of adequate ophthalmologic examination or evaluation to document the pathology.
- Inability or unavailability to undergo follow-up eye exams with the principal investigator or their ophthalmologist as outlined in the protocol.

- Inability to provide informed consent.

- Insufficient compliance in individuals affected by medical conditions, such as multiple sclerosis, epilepsy, Parkinson's disease, diabetes, hypertension, vasculitis, renal and hepatic diseases, dysthyroidism, malignant neoplasias, and other systemic chronic diseases.

For each patient, the diagnosis was established by SD-OCT with Cirrus 5000 (Carl Zeiss Meditec AG, Jena, Germany), microperimetry (MY) with Maia 100809 (CenterVue S.p.A., Padua, Italy), and ocular electrophysiology with the Retimax electromedical system (C.S.O. Srl, Scandicci, Italy). In particular, the average retinal thickness along the horizontal scan $(6 \mathrm{~mm}$.) crossing the fovea and the foveal thickness (FT) was measured in micronmeters $(\mu \mathrm{m})$. Electrical cell activity was recorded in micronVolts by ERG analysis according to the standards set in 2009 by the International Society for Clinical Electrophysiology of Vision (ISCEV) (McCulloch et al., 2015; Nebbioso et al. 2014; Verboschi et al, 2013).

Best corrected visual acuity (BCVA) for far and near distance was evaluated (T0) in all patients. BCVA was measured by early treatment diabetic retinopathy study (EDTRS) charts at 4 meters and expressed in logarithm of the minimum angle of resolution (logMAR) as well as visual acuity for near vision (close-up) in points (Pts) indicating the necessary enlargement factor $(\mathrm{X})$.

All the eyes enrolled in this study were sub-divided into two groups on the basis of central retinal thickness or FT recorded by SD-OCT in: group A (14 eyes) $\leq 190 \mu \mathrm{m}$ and group B (20 eyes) $>190 \mu \mathrm{m}$.

Therefore, an autograft of mesenchimal cells of fat cells and PRP was performed using LRRT (Limoli et al., 2014; Oner et al., 2019; Limoli et al., 2016; Limoli et al., 2017) (Fig. 1). It consists in a graft of the before mentioned mesenchymal cell types, which are adypose cells, adipose derived stem cells (ADSCs)

Table 1

Demographic data of retinitis pigmentosa (RP) patients with foveal thickness $\leq 190 \mu \mathrm{m}$ (Group A) or $>190 \mu \mathrm{m}$ (Group B)

\begin{tabular}{lccc}
\hline Patients & Group $A \leq 190 \mu \mathrm{m}$ & Group $B>190 \mu \mathrm{m}$ & Total \\
\hline Number patients/eyes & $11 / 14$ & $14 / 20$ & $25 / 34$ \\
Age in years $( \pm \mathrm{SD})$ & $42.1(13.30)$ & $49.6(20.82)$ & $45.9(18.36)$ \\
Range & $19-55$ & $24-86$ & $19-86$ \\
F/M & $5(45 \%) / 6(55 \%)$ & $6(43 \%) / 8(11(57 \%)$ & $11(44 \%) / 14(56 \%)$ \\
Eye right/left & $5 / 9$ & $12 / 8$ & $17 / 17$ \\
\hline
\end{tabular}

F: female; M: male. 
contained in the stromal vascular fraction (SVF) of adipose tissue and plateletes (PLT) recovered in the platelet-rich plasma (PRP) (Gentile et al., 2012). Each eye received a graft of orbital fat between the choroid and sclera in a scleral pocket created with deep sclerectomy to expose the surface of the choroidal space (Limoli et al., 2014; Oner et al., 2019; Limoli et al., 2016; Limoli et al, 2017). In particular, we estimated the VP, i.e., BCVA, close-up visus in print size, sensitivity in $\mathrm{dB}$ measured by MY, and visus obtained after rehabilitation through magnifying visual devices in both groups at baseline (T0) and at 6 months (T180).

\subsection{Statistical methods}

Data were presented as mean \pm standard deviation (SD) and minimum and maximum (min-max) values were also reported. Student's $t$-test was used to statistically compare mean age between the two study groups. The Shapiro-Wilk test was used to assess the normality of distribution of the investigated parameters. Mixed regression models with robust errors were applied to analyse the difference between the two groups at T0 and T180. In addition, the effect of the interaction between the group and time was eval-

Table 2

Descriptive characteristics of analysed parameters in the two groups with foveal thickness $\leq 190 \mu \mathrm{m}$ (Group A) $(n=14)$ and $>190 \mu \mathrm{m}$ (Group B) $(n=20)$, at baseline (T0) and after 6 months (T180). Mixed model results

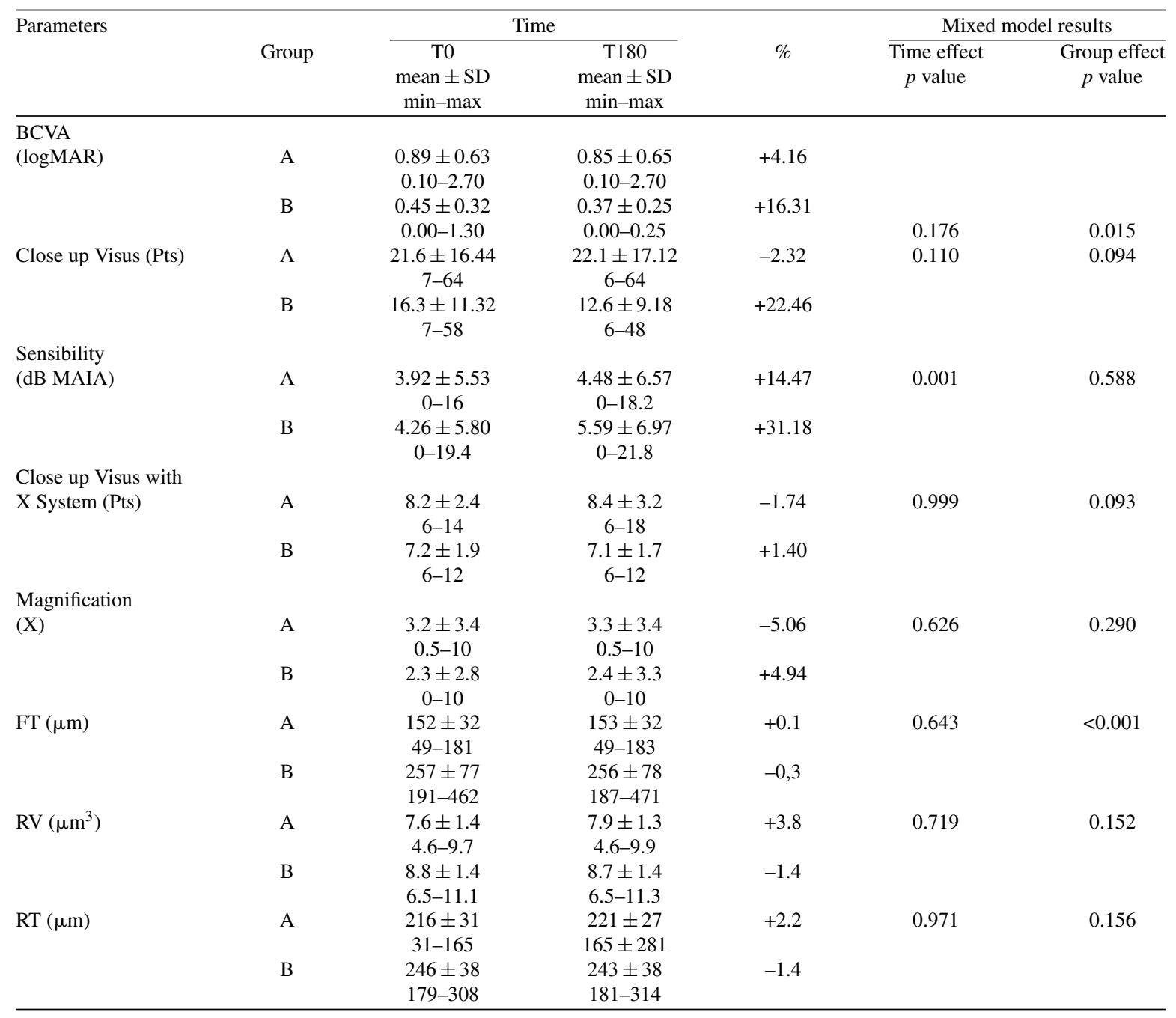

BCVA: Best Corrected Visual Acuity; LogMAR: logarithm of the minimum angle of resolution; Pts: points; dB MAIA: decibel recorded with MAIA microperimetry; FT: foveal thickness; RV: retinal volume; RT: average retinal thickness. Statistical Significance $p=0.05$. 
uated. A $p$ value $<0.05$ was considered statistically significant. All statistical analyses were performed by STATA 14.0 (Collage Station, Texas, USA).

\section{Results}

A total of 34 eyes of 25 patients ( 11 females and 14 males) affected by RP, mean age 45.9 years \pm SD 18.36 (range 19-86 years), were enrolled in the study; the demographic data of the patients are shown in Table 1.

The functional and anatomical visual parameters and the average values recorded at $\mathrm{T} 0$ and $\mathrm{T} 180$ after LRRT surgery are shown in Table 2.

On the basis of FT, 14 out of 34 eyes were classified in group A, FT $\leq 190 \mu \mathrm{m}$, and the remaining 20 eyes were classified in group B, FT > $190 \mu \mathrm{m}$. All 25 patients completed the 6-month follow-up period.

No adverse event associated with the surgery either intra-operatively or post-operatively was observed throughout the period. Mean values of the intraocular pressure recorded before and after surgery did not change significantly.

The group B showed significantly higher mean values than group A in FT, Retinal Volume and average Retinal Thickness (Table 2).

Mean BCVA before treatment was $0.89 \pm 0.63 \mathrm{log}$ MAR (Snellen: 0.23) in group A and $0.45 \pm 0.32$ logMAR (Snellen 0.45) in group B. Specifically,

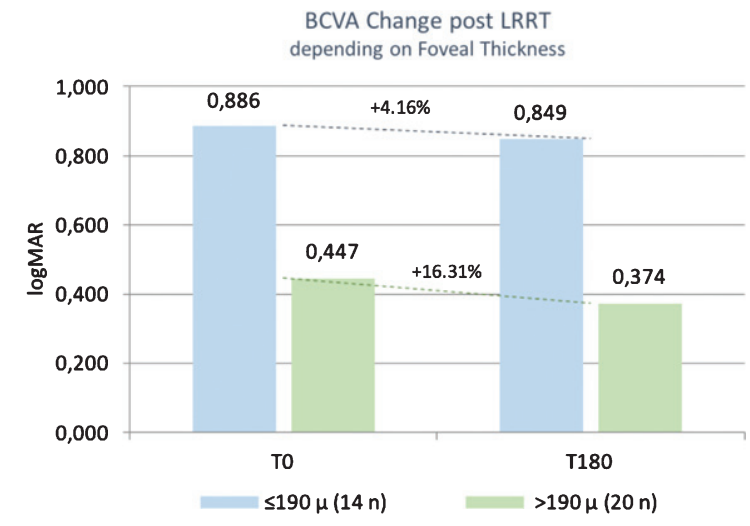

Fig. 2. The best corrected visual acuity (BCVA) was stable after suprachoroidal autograft with Limoli Retinal Restoration Technique (LRRT), or increased $(+16.31 \%)$ in patients with foveal thickness $(\mathrm{FT})>190 \mu \mathrm{m}$.

BCVA in group A varied from 0.89 to $0.85 \log$ MAR $(+4.16 \%-p=0.9701)$, whereas in group $\mathrm{B}$ it was from 0.45 to $0.37 \log$ MAR $(+16.31 \%-p=0.9083)$ (Fig. 2). Percentage variation was lower in group A than in group B. There was no statistically significant difference in visual acuity from baseline within the same group and between the two groups.

At baseline, mean close-up visus was $21.6 \pm 16.44$ pts in group A and 16.3 pts \pm 11.32 in group B. At 6 months follow-up, it decreased to $22.1 \pm 17.12$ pts in group A $(p=0.9224)$, whereas it increased to $12.6 \pm 9.18$ pts in group B $(p=0.3579)$, showing that

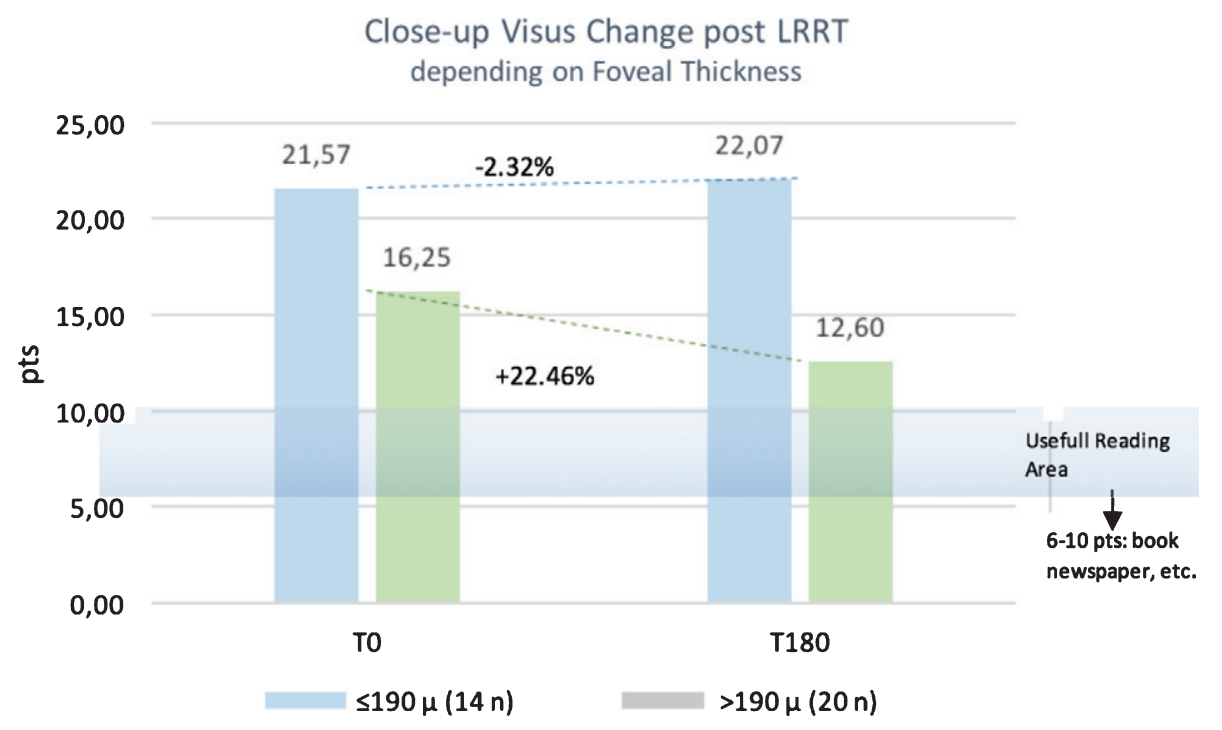

Fig. 3. Residual Close-Up Visus change post Limoli Retinal Restoration Technique (LRRT) depending on foveal thickness. Six months after surgery (T180) the close-up visus was stable if the foveal thickness (FT) $\leq 190 \mu \mathrm{m}$ or increased by $+22.46 \%$ in the group where the FT was $>190 \mu \mathrm{m}$. 
there was a trend tending to significance in the latter group. Percentage variation was negative in group A $(-2.32 \%)$; conversely, it greatly increased in group B (+22.46\%) (Fig. 3).

Average threshold sensitivity at baseline in MY was $3.92 \pm 5.53 \mathrm{~dB}$ in group A and $4.26 \pm 5.80 \mathrm{~dB}$ in group B. In the six-month follow-up, it increased in both groups $4.48 \pm 6.57 \mathrm{~dB}(p=0.85170)$ vs. $5.59 \pm 6.97 \mathrm{~dB}(p=0,85113)$, respectively. Percentage improvement in retinal sensitivity was lower in group A $(+14.47 \%)$ than in group B (+31.18). Despite the improvement in retinal sensitivity, the data were not significant within the same group and between them (Figs. 4-6).

The average threshold of close-up visus with magnifying system at baseline was $8.2 \pm 2.4$ pts with 3.2 $\mathrm{X}$ in group $\mathrm{A}$ and $7.2 \pm 1.9 \mathrm{pts}$ with $2.3 \mathrm{X}$ in group B. In the sixth-month follow-up, it changed in both groups to $8.4 \pm 3.2$ pts with $3.3 \mathrm{X}(p=0.9193) v s$. $7.1 \pm 1.7$ pts with $2.4 \mathrm{X}$ ( $p=0.9167)$, respectively.

Percentage of change was lower in group A $(-1.74 \% \%)$ than in group B $(+1.40 \%)$ (Fig. 7$)$.

In all models, the interaction TimexGroup had no significant effect (Table 3).

Surveying the subjective experience of all patients, at 6 months post LRRT surgery, it was reported that

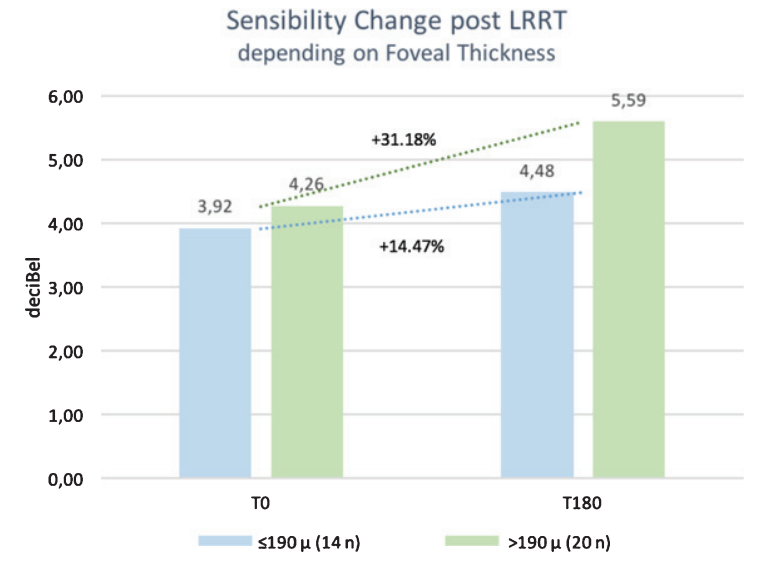

Fig. 4. After stem cell surgery, Limoli Retinal Restoration Technique (LRRT), at 6 months (T180) there was a more relevant change for sensitivity in the group with foveal thickness $>190 \mu \mathrm{m}$ (Group B), recorded with microperimetry.

VP increased in 25 eyes out of $34(73.53 \%)$, remained unvaried in 6 eyes $(17.65 \%)$, and worsened in 3 eyes $(8.82 \%)$ (Table 4).

However, examining patient compliance analysis feedback according to FT, the perception of improvement would be greater for patients with FT $>190 \mu \mathrm{m}$ (18 eyes out of $20-90.00 \%$ ), rather than for patients
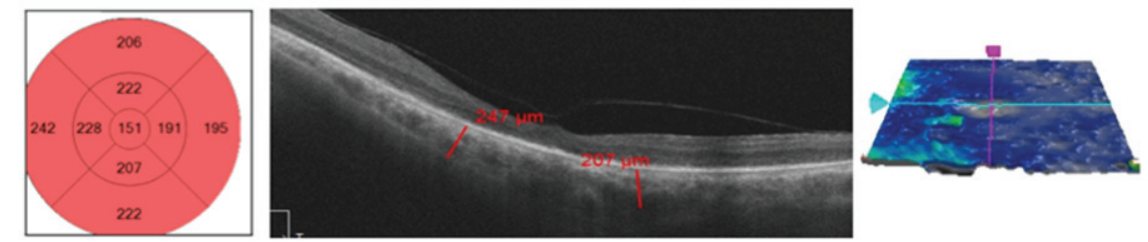

Patient with RP and foveal thickness $<190 \mu$ treated with LRRT
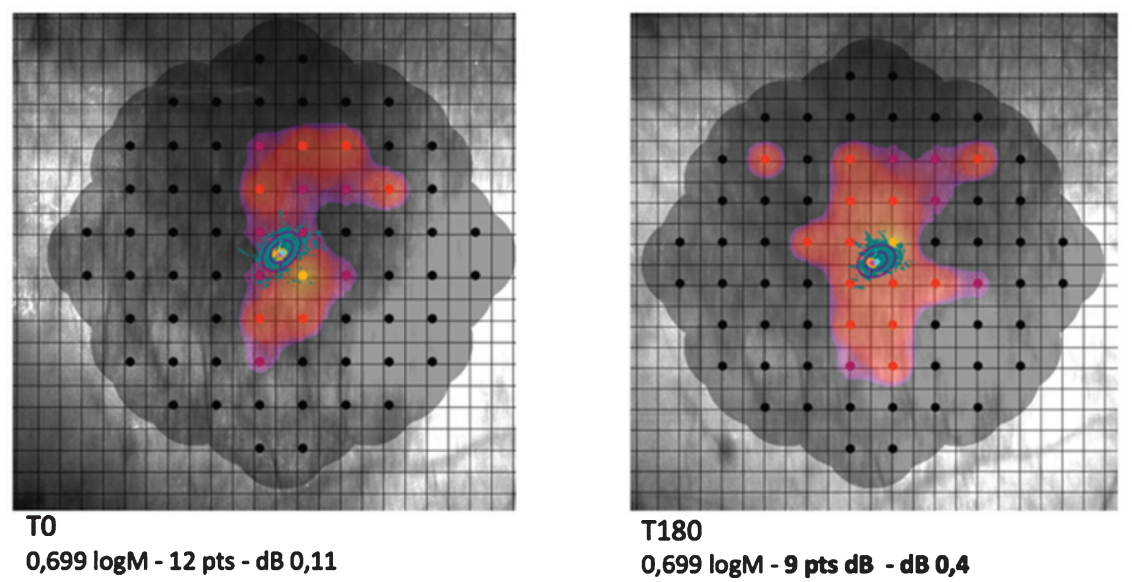

Fig. 5. A thin foveal thickness (FT) $<190 \mu \mathrm{m}$ (Group A), as computed in our study, means that the retinal cell population is small, foveal structures are often dystrophic and the photoreceptor/retinal pigment epithelium/Bruch's membrane/choriocapillaris complex is no longer recognizable. Retinitis pigmentosa (RP). Limoli Retinal Restoration Technique (LRRT). 


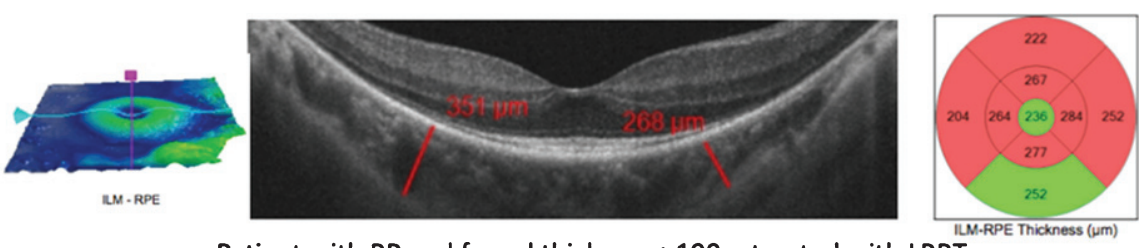

Patient with RP and foveal thickness $>190 \mu$ treated with LRRT

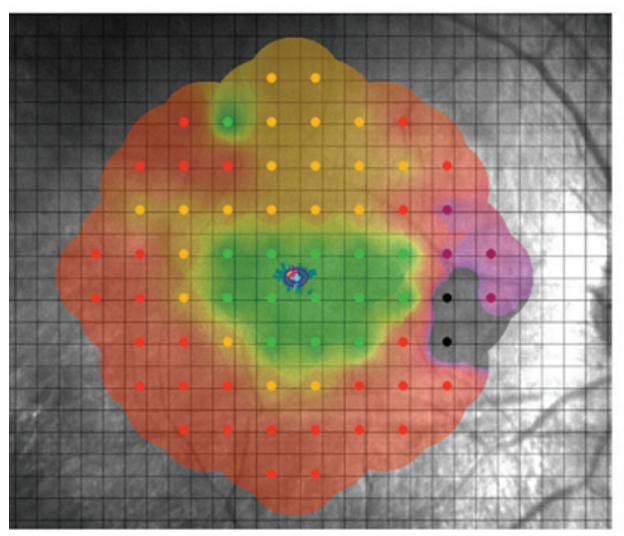

TO

$0,000 \log M-7$ pts - conERG $4,26 \mu V-d B 11,5$

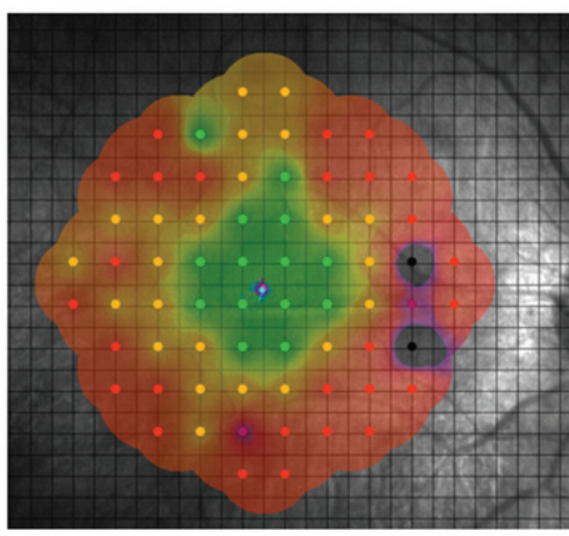

T180

$0,000 \log M 6$ pts - conERG $6,46 \mu \mathrm{V}$ - dB 12,2

Fig. 6. A considerable foveal thickness (FT) $>190 \mu \mathrm{m}$ (Group B), as computed in our study, means that the retinal cell population is still large, foveal structures are still intact and the photoreceptor/retinal pigment epithelium/Bruch's membrane/choriocapillaris complex is recognizable. Mesenchymal cell administration showed the ability to exert a positive influence over functional parameters six months after Limoli Retinal Restoration Technique (LRRT). Retinitis pigmentosa (RP). Photopic electroretinogram (cERG).

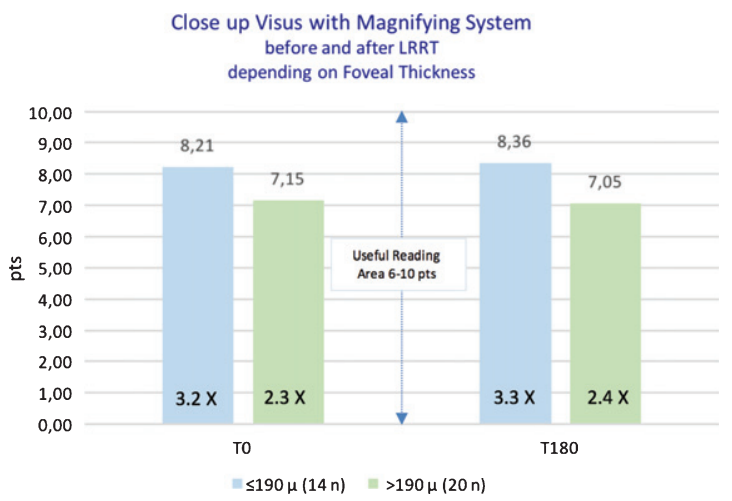

Fig. 7. The average threshold of close-up visus with magnifying system did not show a statistically significant change after cell surgery.

with $\mathrm{FT} \leq 190 \mu \mathrm{m}$ (7 eyes out of $14-50.00 \%$ ) (Fig. 8). Considering only the improved group (25 eyes), 18 eyes (72\%) belonged to group B and 7 (28\%) to group A (Fig. 8).

\section{Discussion}

The LRRT therapy is based on the stabilising effect exerted by cytokines and GFs paracrinally released by the grafted cells. GF-receptor binding on the target cell is the initial step that triggers an intracellular signaling transduction cascade, activating specific second messangers. The latter can activate distinct biochemical pathways generally by a series of phosphorylation events, with the ultimate aim of regulating enzyme activity or gene expression. In particular, the activated transcription factors enter the nucleus and bind directly or indirectly to DNA to regulate the cell transition from G0 to G1 necessary to enter the cellular growth cycle and gene expression, promoting an increased synthesis of proteins, including enzymes and cytokines. These final products play a key role in cell survival, including mitosis, migration, and cellular differentiation (Limoli et al., 2014; Oner et al., 2019; Limoli et al., 2016; Limoli et al., 2017; Limoli, 2014 b; Finklestein and Plmaritoglou, 2001; Garcia et al., 2016).

Mesenchymal cell graft into the sovrachoroidal space promotes a continuous paracrine incretion of GFs that can interfere positively with the evolution of RP in several ways. The therapeutic mechanisms are summarized as follows:

1. Hemorheological activity that contributes to restoring effective retinal perfusion. (Cam- 
Table 3

Variation between the two times at baseline (T0) and after 6 months (T180) estimated by mixed model in the two groups with foveal thickness $\leq 190 \mu \mathrm{m}$ (Group A) and $>190 \mu \mathrm{m}$ (Group B)

\begin{tabular}{lccc}
\hline Variation (T180-T0) & $\mathrm{A} \leq 190 \mu \mathrm{m}$ & $\mathrm{B}>190 \mu \mathrm{m}$ & $n=20$ \\
Mean \pm SD & $n=14$ & $\begin{array}{c}\text { Interaction effect } \\
p \text { value }\end{array}$ \\
\hline BCVA (logMAR) & $0.037 \pm 0.144$ & $-0.073 \pm 0.288$ & 0.715 \\
Close up Visus (Pts) & $-0.5 \pm 17.1$ & $-3.15 \pm 9,2$ & 0.089 \\
Sensibility (dB MAIA) & $0.57 \pm 1.18$ & $1.02 \pm 1.76$ & 0.163 \\
Close up Visus with X System (Pts) & $-0.14 \pm 2.60$ & $0.1 \pm 1.30$ & 0.738 \\
Magnification (X) & $-0,16 \pm 0.47$ & $-0.11 \pm 2,02$ & 0.920 \\
FT $\left(\mu \mathrm{m}^{3}\right.$ & $0 \pm 7.18$ & $-1 \pm 5.19$ & 0.624 \\
RV $\left(\mu \mathrm{m}^{3}\right)$ & $0.3 \pm 0.76$ & $-0.1 \pm 0.72$ & 0.113 \\
RT $(\mu \mathrm{m})$ & $5 \pm 5.19$ & $-3 \pm 19.71$ & 0.145 \\
\hline
\end{tabular}

BCVA: Best Corrected Visual Acuity; LogMAR: logarithm of the minimum angle of resolution; Pts: points; dB MAIA: decibel recorded with MAIA microperimetry; FT: foveal thickness; RV: retinal volume; RT: average retinal thickness. Statistical Significance $p=0.05$.

pochiaro, 2018; Yi et al., 2018; Beutelspacher et al., 2011; Jurk and Kehrel, 2005; Mammoto et al., 2016; Cervelli et al., 2013; Çerman et al., 2016; Rajashekhar et al., 2014; Ezquer et al., 2016; Shen et al., 2005; Yang et al., 2018).

2. Anti-oxidative activity to prevent oxygeninduced photoreceptor cell death in the posterior retina, which remains thicker than the peripheral retina (Punzo et al., 2011; Yang et al., 2009; AïtAli et al., 2015; Byrne et al., 2015; Zeiss and Johnson, 2004;

3. Anti-inflammatory activity as the activation of microglia occurs simultaneously or just before the peak of apoptotic photoreceptor death in RP, assuming that microglia may be involved in the pathogenesis of RP (Gupta et al., 2003; Zeng et al., 2005; Peng et al., 2014).

4. Anti-apoptotic activity regulated by cytokines that can either inhibit or induce apoptosis (Cui et al., 2016; Athanasiou et al., 2013).

5. Cytoprotective activity of the GFs that contributes to neuroprotection by regulating photoreceptor metabolic activity, extensively impaired in RP (Shen et al., 2015; Cui et al., 2016; Gasperi and Castellano, 2010; Chung et al., 2016; Kim et al., 2003; Ueki and Reh, 2013; Hauk et al., 2006).

It is important to note that the boundaries among these mechanisms are not clearly distinguishable.

In recent years, the synergy between cellular therapies and electrical stimulation has begun to be considered as a possible treatment for degenerative pathologies. This synergy addresses four main aspects: native cell survival, transplanted cell survival, transplanted cell integration, and functional
Table 4

Compliance analysis after 6 months (T180) in the two groups with foveal thickness $\leq 190 \mu \mathrm{m}$ (Group A) and > $190 \mu \mathrm{m}$ (Group B)

\begin{tabular}{|c|c|c|c|c|c|c|}
\hline \multirow{2}{*}{$\begin{array}{l}\text { Compliance } \\
\text { Improved } \\
\end{array}$} & \multicolumn{2}{|r|}{$\begin{array}{c}\text { A } \\
n=14\end{array}$} & \multicolumn{2}{|c|}{$\begin{array}{c}\text { B } \\
n=20\end{array}$} & \multicolumn{2}{|c|}{ Total eyes } \\
\hline & $\overline{7}$ & $50.00 \%$ & 18 & $90.00 \%$ & 25 & $73.53 \%$ \\
\hline Unchanged & 5 & $35.71 \%$ & 1 & $5.00 \%$ & 6 & $17.65 \%$ \\
\hline Worsened & 2 & $14.29 \%$ & 1 & $5.00 \%$ & 3 & $8.82 \%$ \\
\hline
\end{tabular}

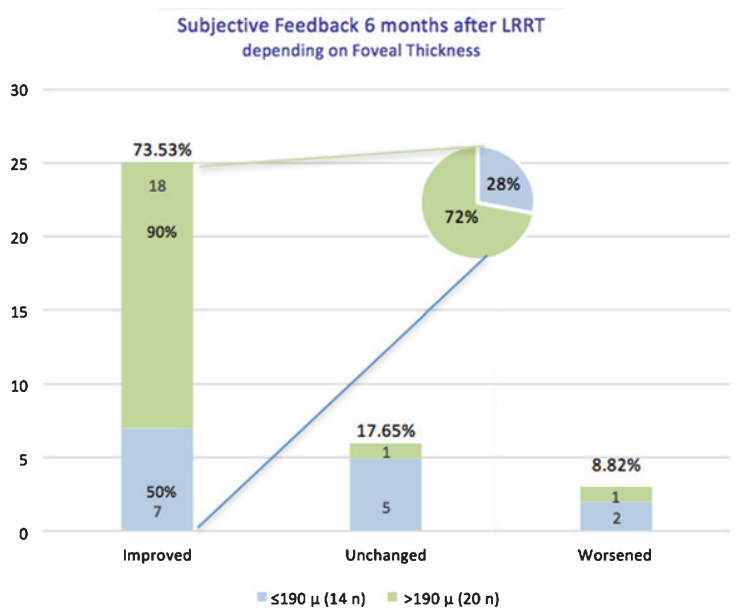

Fig. 8. Compliance analysis of retinitis pigmentosa (RP) patients at 6 months (T180) post Limoli Retinal Restoration Technique (LRRT) depending on foveal thickness: compliance was good in $73.53 \%$ of all cases (both Groups A and B). Patients reported to see better 6 months after surgery, but the percentage reached $90 \%$ in those with FT $>190 \mu \mathrm{m}$. If we considered only the improved group ( 25 eyes), 18 eyes ( $72 \%$ ) belonged to Group B and 7 eyes (28\%) to Group A.

synapse formation/axon regeneration (Manthey et al., 2017).

While the methods of Electrical Stimulation (ES) administration are different, their influence on the 
preservation of retinal structure and function is similar and based on studies in animal models. In the rat model of retinitis pigmentosa (RP), it has been shown that ES preserved outer nuclear layer (ONL) thickness and delayed inner retinal degeneration (Manthey et al., 2017; Hanif et al., 2016).

Similarly, ES-treated rat retinas exhibited decreased apoptosis when isolated ex vivo and weekly sessions of one-hour ES therapy evoked preservation of ONL thickness (Pardue et al., 2005; Ciavatta et al, 2013). Light-induced retinal degeneration models have also been proven to preserve retinal structure after ES stimulation, reducing photoreceptor cell death, and preserve outer segment length (Schmid et al., 2012; Morimoto et al., 2007).

RP patients subjected to ES experienced preservation of visual field area and ERG b-wave amplitude (Schmid et al., 2009; Morimoto et al., 2007; Schatz et al., 2012).

Retinal ES technique may be considered a pretreatment to modulate retinal cell function because recent advances have shown that it can prime the host environment for cell transplantation.

Consequently, it can be assumed that ES treatment may create a more balanced and less hostile environment, modifying the secretion of the neurotrophic factors (Sabel 2018).

ES conditions up-regulation of neurotrophic factors in Müller cells, normally involved in this protection mechanism (Morimoto et al., 2007; Schatz et al., 2012). Increased in-vivo expression of fibroblast growth factor beta (FGF-2), insulin growth factor-1 (IGF-1), and brain derived neurotrophic factor (BDNF) have been observed after ES (Schmid et al., 2009; Morimoto et al., 2007; Schatz et al., 2012; Schatz et al., 2011; Zhou et al., 2012). Furthermore, ES down-regulates pro-inflammatory cytokines like tumor necrosis factor (TNF)-alpha, interleukin- 1 beta (IL-1 $\beta$ ) and the pro-apoptotic gene Bax (Morimoto et al., 2007; Ciavatta et al., 2009). The release of neurotrophic factors from the post-synaptic membrane made possible by neuromodulation, together with the enrichment of the same factors in the extracellular environment operated by autologous grafts, determines the formation of synapses at pre-synaptic level, facilitating and strengthening neurotransmission. The synaptogenesis process could be ignited both by the mesenchymal cell grafts and the pulsed neuromodulation that cause the rhythmic formation of action potentials (Ciavatta et al., 2009; Miyake et al., 2007). ES can be performed before or after Cell Surgery and its direct effect have been evaluated up to now only in
CNS-derived tissue injuries, such as brain and spinal cord traumas, but not yet in the retina. For example, this type of combination therapy was performed in a spinal cord injury model in rats and showed to enhance locomotor function and to increase survival $(31.3 \pm 4.6 \%$ compared to $26.7 \pm 2.5 \%$ in unstimulated transplants), differentiation, and integration of the transplanted cells as well as axonal regeneration, as assessed by the enhancement of somatosensoryevoked potentials (Miyake et al., 2007; Liu et al., 2012).

In addition, Matsumoto et al. (2013) have reported that performing ES in vitro prior to BM-MSCs transplantation can increase levels of neural markers at day 7 [nestin and paired box protein 6 (Pax6)] and day 14 [neurofilament heavy (NF-H) and microtubule-associated protein 2 (MAP2)] in culture. The enhancement of Cell Surgery by ES has also been observed during muscle reinnervation after sciatic injury using transplanted neurons and myocardial regeneration following ischemic heart failure (Matsumoto et al., 2013). The latter can be explained by the stimulation and production of exosomes that contain cardioprotective molecules (Liu et al., 2012; Matsumoto et al., 2013; Grumbles et al. 2013; Huang et al., 2011). In particular, exosomes are useful tools for cell-cell communication in the normal and diseased retina (Campbell et al., 2016; Locke et al., 2014; Atienzar-Aroca et al., 2016) and exert different biological actions depending on their host cell. In fact, it is possible that exosomes may play a critical role in the ES-induced changes in chorioretinal blood flow observed after treatment (Atienzar-Aroca et al., 2016; Wang et al., 2009).

Kurimoto et al. (Kurimoto et al., 2010) studied the chorioretinal blood flow in 10 healthy subjects before and after this type of combination therapy using laser speckle flowgraphy and showed that it promotes and increases chorioretinal blood flow in the area around the macula and midway between the optic disc and macula, but not around the optic disc itself.

However, the poorer the cellular condition in patients with RP is, the more modest the response by the residual cells and the lower the cellular conservation than that achievable with ES if performed early. The implantation of mesenchymal cells in the suprachoroidal space makes the necessary GFs available in more effective quantities to the retinal environment directly and indirectly (RPE and Müller Cells). It can be said that cellular surgery and microelectric stimulation have complementary and synergistic functions. 
Therefore, the dual application of stem cell therapy and a controllable electrical current may provide a novel mechanism to realize the full advantages of Cell Surgery for retinal repair.

Considered together, the combination of ES and LRRT therapy to treat retinal degenerative diseases may have two primary benefits: (1) increased trophic support by the remaining endogenous retinal cells resulting in improved habitability of the host environment and (2) an enhancement of the differentiation, integration, and synapse formation of the autografted MSCs and remaining endogenous neurons.

\section{Conclusion}

LRRT cell therapy has been demonstrated to have a notable impact on certain functional parameters after the interaction with residual cells. The direct contact of the autograft with the choroid enhances the incretion of the bioactive factors produced by mesenchimal cells into the choroidal flow and therefore promotes a widespread dissemination through the retinal tissue, finally exuding in vitreous body.

Remarkably, BCVA, residual close-up visus and sensibility improved, following LRRT, in the group in which FT is already greater compared to the group with lower FT.

No modifications in reading ability obtained with magnifying systems prescribed before surgery have been observed.

Three quarters of patients reported to see better 6 months after LRRT, but the percent reached $90 \%$ in those with FT $>190 \mu \mathrm{m}$.

The results of our study demonstrate the therapeutic potential of MSCs surgery by LRRT, which would directly and indirectly increase choroidal perfusion as well as contribute to a greater trophism of photoreceptors through GF-receptor interactions and Müller cell and RPE-mediated stimulation. It is considered that the interaction between retinal cells and GFs can lead to an improvement in the outlook for RP, to prevent and/or delay its progression.

In our study, the group with a FT $>190 \mu \mathrm{m}$ is associated with a better prognosis. On the other hand, the lack of cells has proven to hinder the desired interactions between GFs and membrane receptors.

FT in RP gives an objective indication of the number of cells in the fovea and although the foveal area appears normal, retinal thickness and macular volume may be reduced. Hence, FT indicates indirectly the trophic condition of residual photoreceptors in RP and can be used as a prognostic criterion in predicting the therapeutic response of LRRT cell autograft.

The rehabilitator and surgeon should be aware of cellularity of retina in RP patients treated with cell therapy.

A major limitation of our study was the lack of molecular characterisation of the sample which was considered. Genetic diagnosis is sure to become more relevant in coming years and it will be possible to determine the impact of MCS administration on RP different genetic groups.

Therefore, we can conclude that, despite the heterogeneity of the enrolled subjects and the lack of molecular diagnostics, autologous mesenchymal cell graft into the suprachoroidal space can sustain retinal neuroenhancement especially in patients with an adequate FT. Consequently, LRRT surgery could improve the clinical and rehabilitative prognostic aspects in RP patients associating, particularly, the treatment with ES to foster a beneficial synergic activity. On the other hand, further clinical research and studies with a longer follow-up will be needed to evaluate its efficacy.

\section{References}

Aï-Ali, N., Fridlich, R., Millet-Puel, G., Clérin, E., Delalande, F., Jaillard, C., Blond, F., Perrocheau, L., Reichman, S., Byrne, L.C., Olivier-Bandini, A., Bellalou, J., Moyse, E., Bouillaud, F., Nicol, X., Dalkara, D., van Dorsselaer, A., Sahel, J.A., \& Léveillard, T. (2015). Rod-derived cone viability factor promotes cone survival by stimulating aerobic glycolysis. Cell, 161(4), 817-32.

Aizawa, S., Mitamura, Y., Baba, T., Hagiwara, A., Ogata, K., \& Yamamoto, S. (2009). Correlation between visual function and photoreceptor inner/outer segment junction in patients with retinitis pigmentosa. Eye (London), 23, 304-308.

Anitua, E., Andia, I., Ardanza, B., Nurden, P., \& Nurden, A. T. (2004). Autologous platelets as a source of proteins for healing and tissue regeneration. Thrombosis and Haemostasis, 91(1), 4-15.

Antoniades, H. N., \& Williams, L. T. (1983). Human plateletderived growth factor: structure and function. Federation Proceedings, 42(9), 2630-2634.

Athanasiou, D., Aguilà, M., Bevilacqua, D., Novoselov, S. S., Parfitt, D. A., \& Cheetham, M. E. (2013). The cell stress machinery and retinal degeneration. FEBS Letters, 587, 20082017.

Atienzar-Aroca, S., Flores-Bellver, M., Serrano-Heras, G., Martinez-Gil, N., Barcia, J. M., Aparicio, S., Perez-Cremades, D., Garcia-Verdugo, J. M., Diaz-Llopis, M., Romero, F. J., \& Sancho-Pelluz, J. (2016). Oxidative stress in retinal pigment epithelium cells increases exosome secretion and promotes angiogenesis in endothelial cells. Journal of Cellular and Molecular Medicine, 20(8), 1457-66. 
Baddour, J. A., Sousounis, K., \& Tsonis, P. A. (2012). Organ repair and regeneration: an overview. Birth Defects Research, 96(1), $1-29$.

Beutelspacher, S. C., Serbecic, N., Barash, H., Burgansky-Eliash, Z., Grinvald, A., Krastel, H., \& Jonas, J. B. Retinal blood flow velocity measured by retinal function imaging in retinitis pigmentosa (2011). Graefe's Archive for Clinical and Experimental Ophthalmology, 249, 1855-1858.

Byrne, L. C., Dalkara, D., Luna, G., Fisher, S. K., Clerin, E., Sahel, J. A. Leveillard, T., \& Flannery, J. G. (2015) Viralmediated RdCVF and RdCVFL expression protects cone and rod photoreceptors in retinal degeneration. Journal of Clinical Investigation, 125(1), 105e116.

Campbell, C. R., Berman, A. E., Weintraub, N. L., \& Tang, Y. L. (2016). Electrical stimulation to optimize cardioprotective exosomes from cardiac stem cells. Medical Hypotheses, 88, 6-9.

Campochiaro, P. A. \& Mir, T. A. (2018). The mechanism of cone cell death in Retinitis Pigmentosa. Progress in Retinal and Eye Research, 62, 24e 37 .

Çerman, E., Akkoç, T., Eraslan, M., Sahin, Ö., Özkara, S., Aker, F. V., Subasí, C., Karaöz, E., \& Akkoç, T. (2016) Retinal electrophysiological effects of intravitreal bone marrow derived mesenchymal stem cells in streptozotocin induced diabetic rats. PLOS ONE, 11, e0156495.

Cervelli, V., Bocchini, I., Di Pasquali, C., De Angelis, B., Cervelli, G., Curcio, C. B., Orlandi, A., Scioli, M. G., Tati, E., Delogu, P., \& Gentile, P. (2013). P.R.L. platelet rich lipotransfert: our experience and current state of art in the combined use of fat and PRP. BioMed Research International, 2013, 434191.

Chung, S., Rho, S., Kim, G., Kim, S. R., Baek, K. H., Kang, M., \& Lew, H. (2016). Human umbilical cord blood mononuclear cells and chorionic plate-derived mesenchymal stem cells promote axon survival in a rat model of optic nerve crush injury. International Journal of Molecular Medicine, 37, 1170-1180.

Ciavatta, V. T., Kim, M., Wong, P., Nickerson, J. M., Shuler, R. K., McLean, G. Y., \& Pardue, M. T. (2009). Retinal expression of Fgf2 in RCS rats with subretinal microphotodiode array. Investigative Ophthalmology \& Visual Science, 50, 4523-4530.

Ciavatta, V. T., Mocko, J. A., Kim, M. K., \& Pardue, M. T. (2013). Subretinal electrical stimulation preserves inner retinal function in RCS rat retina. Molecular Vision, 19, 995-1005.

Cui, Y., Xu, N., Xu, W., \& Xu, G. (2016). Mesenchymal stem cells attenuate hydrogen peroxide-induced oxidative stress and enhance neuroprotective effects in retinal ganglion cells. In Vitro Cellular \& Developmental Biology, 53, 328-335.

Ding, S. L. S., Kumar, S., \& Mok, P. L. (2017). Cellular Reparative Mechanisms of Mesenchymal Stem Cells for Retinal Diseases. International Journal of Molecular Medicine, 18, 1406.

Emre, E., Yüksel, N., Duruksu, G., Pirhan, D., Subaşi, C., Erman, G., \& Karaöz, E. (2015). Neuroprotective effects of intravitreally transplanted adipose tissue and bone marrow-derived mesenchymal stem cells in an experimental ocular hypertension model. Cytotherapy, 17(5), 543-59.

Ezquer, M., Urzua, C. A., Montecino, S., Leal, K., Conget, P., \& Ezquer, F. (2016). Intravitreal administration of multipotent mesenchymal stromal cells triggers a cytoprotective microen- vironment in the retina of diabetic mice. Stem Cell Research \& Therapy, 7, 42 .

Finklestein, S., \& Plomaritoglou, A. Growth factors. In Miller, L. P., \& Hayes, R. L. (2001). Head Trauma: Basic, Preclinical, and Clinical Directions. New York: Wiley, 165-187.

Fisher, M. D., Fleishhauer, J. C., Gillies, M. C., Sutter, F. K., Helbig, H., \& Barthelmes, D. (2008). A new method to monitor visual field defects caused by photoreceptor degeneration by quantitative optical coherence tomography. Investigative Ophthalmology \& Visual Science, 49, 3617-3621.

Garcia, T. B., Hollborn, M., \& Bringmann, A. (2017). Expression and signaling of NGF in the healthy and injured retina. Cytokine Growth Factor Reviews, 34, 43-57.

Gasperi, M., \& Castellano, A. E. (2010). Growth hormone/insulinlike growth factor I axis in neurodegenerative diseases. Journal of Endocrinological Investigation, 33(8),587-91.

Gentile, P., Orlandi, A., Scioli, M. G., Di Pasquali, C., Bocchini, I., Curcio, C. B., Floris, M., Fiaschetti, V., Floris, R., \& Cervelli, V. (2012). A Comparative Translational Study: The Combined Use of Enhanced Stromal Vascular Fraction and Platelet-Rich Plasma Improves Fat Grafting Maintenance in Breast Reconstruction, Stem Cells Translational Medicine, 1, 341-351.

Grumbles, R. M., Liu, Y., Thomas, C. M., Wood, P. M., \& Thomas, C. K. (2013). Acute stimulation of transplanted neurons improves motoneuron survival, axon growth, and muscle reinnervation. Journal of Neurotrauma, 30(12),1062-9.

Guadagni, V., Novelli, E., \& Strettoi, E. (2015). Environmental enrichment reduces photoreceptor degeneration and retinal inflammation in a mouse model of retinitis pigmentosa. Investigative Ophthalmology \& Visual Science, 33(9),1017710192.

Gupta, N., Brown, K. E., \& Milam, A. H. (2003). Activated microglia in human retinitis pigmentosa, late-onset retinal degeneration, and agerelated macular degeneration. Experimental Eye Research, 76, 463-71.

Hamel, C. (2006). Retinitis pigmentosa. Orphanet Journal of Rare Diseases, 1, 40.

Hanif, A. M., Kim, M. K., Thomas, J. G., Ciavatta, V. T., Chrenek, M., Hetling, J. R., \& Pardue, M. T. (2016). Whole-eye electrical stimulation therapy preserves visual function and structure in P23H-1 rats. Experimental Eye Research, 149, 75-83.

Hartong, D. T., Berson, L., \& Dryja, T. P. (2006). Retinitis pigmentosa. Lancet, 368, 1795-1809.

Hauck, S. M., Kinkl, N., Deeg, C. A., Swiatek-de Lange, M., Schöffmann, S., Ueffing, M. (2006). GDNF family ligands trigger paracrine neuroprotective signalling in retinal glial cells. Molecular and Cellular Biology, 26(7), 2746-57.

He, Y., Zhang, Y., Liu, X., Ghazaryan, E., Li, Y., Xie, J., \& Su, G. (2014). Recent advances of stem cell therapy for retinitis pigmentosa. International Journal of Molecular Sciences, 15 , 14456-74

Herse, P. (2005). Retinitis pigmentosa: visual function and multidisciplinary management. Clinical \& Experimental Optometry, 88, 335-350.

Hofer, H. R., \& Tuan, R. S. (2016). Secreted trophic factors of mesenchymal stem cells support neurovascular and musculoskeletal therapies. Stem Cell Research \& Therapy, 7(1),131. 
Hood, D. C., Lin, C. E., Lazow, M. A., Locke, K. G., Zhang, X., \& Birch, D. G. (2009). Thickness of receptor and postreceptor retinal layers in patients with retinitis pigmentosa measured with frequency-domain optical coherence tomography. Investigative Ophthalmology \& Visual Science, 50, 2328 -2336 .

Huang, G., Pashmforoush, M., Chung, B., \& Saxon, L.A. (2011). The role of cardiac electrophysiology in myocardial regenerative stem cell therapy. Journal of Cardiovascular Translational Research, 4(1), 61-5.

Huo, D. M., Dong, F. T., Yu, W. H., \& Gao, F. (2010). Differentiation of mesenchymal stem cell in the microenviroment of retinitis pigmentosa. International Journal of Ophthalmology, 3, 216-9.

Idelson, M., Alper, R., Obolensky, A., Ben-Shushan, E., Hemo, I., Yachimovich-Cohen, N., Khaner, H., Smith, Y., Wiser, O., Gropp, M., Cohen, M. A., Even-Ram, S., Berman-Zaken, Y., Matzrafi, L., Rechavi, G., Banin, E., \& Reubinoff, B. (2009). Directed differentiation of human embryonic stem cells into functional retinal pigment epithelium cells. Cell Stem Cell, 5, 396-408.

Johnson, T. V., Dekorver, N. W., Levasseur, V. A., Osborne, A., Tassoni, A., Lorber, B., Heller, J. P., Villasmil, R., Bull, N. D., Martin, K. R., \& Tomarevet S, I. (2014). Identification of retinal ganglion cell neuroprotection conferred by plateletderived growth factor through analysis of the mesenchymal stem cell secretome. Brain, 137(Pt 2), 503-19.

Jurk, K., \& Kehrel, B. E. (2005). Platelets: physiology and biochemistry. Seminars in Thrombosis and Hemostasis, 31, 381-392.

Kim, S. Y., Mocanu, C., McLeod, D. S, Bhutto, I. A., Merges, C., Eid, M., Tong, P., \& Lutty, G. A. (2003). Expression of pigment epithelium-derived factor (PEDF) and vascular endothelial growth factor (VEGF) in sickle cell retina and choroid. Experimental Eye Research, 77, 433-445.

Klassen, H. (2015). Stem cells in clinical trials for treatment of retinal degeneration. Expert Opinion on Biological Therapy, $16,7-14$.

Kurimoto, T., Oono, S., Oku, H., Tagami, Y., Kashimoto, R., Takata, M., Okamoto, N., Ikeda, T., \& Mimura, O. (2010). Transcorneal electrical stimulation increases chorioretinal blood flow in normal human subjects. Clinical Ophthalmology, 4, 1441-6.

Kyurkchiev, D., Bochev, I., Ivanova-Todorova, E, Mourdjeva, M., Oreshkova, T., Belemezova, K., \& Kyurkchiev, S. (2014). Secretion of immunoregulatory cytokines by mesenchymal stem cells. World Journal of Stem Cells, 6(5),552-570.

Langmann, T. (2007). Microglia activation in retinal degeneration. Journal of Leukocyte Biology, 81, 1345-1351

Liang, F. Q., Aleman, T. S., Dejneka, N. S., Dudus, L., Fisher, K. J., Maguire, A. M., Jacobson, S. G., \& Bennett, J. (2001). Long-term protection of retinal structure but not function using rAAV. CNTF in animal models of retinitis pigmentosa. Molecular Therapy, 4, 461-472.

Limoli, P. G. (2014). The retinal cell-neuroregeneration. Principles, applications and perspectives. Limoli Retina Regeneration Tecnique, 407-424.

Limoli, P. G., Limoli, C., Vingolo, E. M., Scalinci, S. Z., \& Nebbioso, M. (2016). Cell surgery and growth factors in dry age-related macular degeneration: visual prognosis and morphological study. Oncotarget, 7(30),46913-46923.

Limoli, P. G., Vingolo, E. M., Morales, M. U., Nebbioso, M., \& Limoli, C. (2014). Preliminary Study on Electrophysiological Changes After Cellular Autograft in Age-Related Macular Degeneration. Medicine, 93(29), e355.

Limoli, P. G., Limoli, C., Vingolo, E. M., Limoli, C., Scalinci, S. Z., \& Nebbioso, M. (2018). Regenerative Therapy by Suprachoroidal Cell Autograft in Dry Age-Related Macular Degeneration: Preliminary in Vivo Report. Journal of Visualized Experiments, 132, e56469.

Lindroos, B., Suuronen, R., \& Miettinen, S. (2010). The potential of adipose stem cells in regenerative medicine. Stem Cell Reviews and Reports, 7, 269-291.

Liu, H., Yang, K., Xin, T., Wu, W., \& Chen, Y. (2012). Implanted electro-acupuncture electric stimulation improves outcome of stem cells' transplantation in spinal cord injury. Artificial Cells Blood Substitutes and Biotechnology, 40(5), 331-7.

Liu, G., Liu, X., Li, H., Du, Q., \& Wang, F. (2016). Optical coherence tomographic analysis of retina in retinitis pigmentosa patients. Ophthalmic Research, 56, 111-122.

Locke, C. J., Congrove, N. R., Dismuke, W. M., Bowen, T. J., Stamer, W. D., \& McKay, B.S. (2014). Controlled exosome release from the retinal pigment epithelium in situ. Experimental Eye Research, 129, 1-4.

Luo, S., Hao, L., Li, X., Dongmei, Y., Diao, Z., Ren, L., \& Xu, H. (2013). Adipose tissue-derived stem cells treated with estradiol enhance survival of autologous fat transplants. The Tohoku Journal of Experimental Medicine, 231, 101-110.

Mammoto, T., Jiang, A., Jiang, E., \& Mammoto, A. (2013). Platelet rich plasma extract promotes angiogenesis through the angiopoietin1-Tie2 pathway. Microvascular Research, 89, $15-24$.

Manthey, A. L., Liu, W., Jiang, Z. X., Lee, M. H. K., Ji, J., So, K. F., Lai, J. S. M., Lee, V. W. H., \& Chiu, K. (2017). Using electrical stimulation to enhance the efficacy of cell transplantation therapies for neurodegenerative retinal diseases: Concepts, challenges, and future perspectives. Cell Transplant, 26(6), 949-965.

Matsumoto, M., Imura, T., Fukazawa, T., Sun, Y., Takeda, M., Kajiume, T., Kawahara, Y., \& Yuge, L. (2013). Electrical stimulation enhances neurogenin 2 expression through betacatenin signaling pathway of mouse bone marrow stromal cells and intensifies the effect of cell transplantation on brain injury. Neuroscience Letters, 533, 71-6.

McCulloch, D. L., Marmor, M. F., Brigell, M. G., Hamilton, R., Holder, G.E., Tzekov, R., \& Bach, M. (2015). ISCEV Standard for full-field clinical electroretinography. Documenta Ophthalmologica, 130, 1-1.

Mead, B., Logan, A., Berry, M., Leadbeater, W., \& Scheven, B. A. (2014). Paracrine-mediated neuroprotection and neuritogenesis of axotomised retinal ganglion cells by human dental pulp stem cells: comparison with human bone marrow and adiposederived mesenchymal stem cells. PLoS ONE, 9(10), e109305.

Jones, M. K., Lu, B., Girman, S., \& Wang, S. (2017). Cell-based therapeutic strategies for replacement and preservation in retinal degenerative diseases. Progress in Retinal and Eye Research, 58, 1-27. 
Mishra, A., Velotta, J., Brinton, T. J., Wang, X., Chang, S., Palmer, O., Sheikh, A., Chung, J., Yang, P. C., Robbins, R., \& Fischbein, M. (2011). RevaTen platelet-rich plasma improves cardiac function after myocardial injury. Cardiovascular Revascularization Medicine, 12(3), 158-163.

Miyake, K., Yoshida, M., Inoue, Y., \& Hata, Y. (2007). Neuroprotective effect of transcorneal electrical stimulation on the acute phase of optic nerve injury. Investigative Ophthalmology \& Visual Science, 48, 2356-2361.

Mizuno, H. (2009). Adipose-derived stem cells for tissue repair and regeneration: ten years of research and a literature review. Journal of Nippon Medical School, 76(2), 56-66.

Moraes, L., Vasconcelos-dos-Santos, A., Santana, F. C., Godoy, M. A., Rosado-de-Castro, P. H., Azevedo-Pereira, J. R. L., Monteiro Cintra, W., Gasparetto, E. L., Santiago, M. F., \& Mendez-Otero, R. (2012). Neuroprotective effects and magnetic resonance imaging of mesenchymal stem cells labeled with SPION in a rat model of Huntington's disease. Stem Cell Research, 9(2), 143-55.

Nakagami, H., Morishitah, R., Maeda, K., Kikuchi, Y., Ogihara, T., \& Kaneda, Y. (2006). Adipose tissue-derived stromal cells as a novel option for regenerative cell therapy. Journal of Atherosclerosis and Thrombosis, 13, 77-81.

Nebbioso, M., Barbato, A., \& Pescosolido, N. (2014). Scotopic microperimetry in the early diagnosis of age-related macular degeneration: preliminary study. BioMed Research International, 2014, 671529.

Morimoto, T., Fujikado, T., Choi, J. S., Kanda, H., Miyoshi, T., Fukuda, Y., \& Tano, Y. (2007). Transcorneal electrical stimulation promotes the survival of photoreceptors and preserves retinal function in royal college of surgeons rats. Investigative Ophthalmology \& Visual Science, 48, 4725-4732.

Nebbioso, M., Scarsella, G., Tafani, M., \& Pescosolido, N. (2013). Mechanisms of ocular neuroprotection by antioxidant molecules in animal models. Journal of Biological Regulators and Homeostatic Agents, 27(1), 197-209.

Oner, A., Gonen, Z. B., Sevim, D. G., Sinim Kahraman, N., \& Unlu, M. (2019). Six-month results of suprachoroidal adipose tissue-derived mesenchymal stem cell implantation in patients with optic atrophy: a phase 1/2 study. International Ophthalmology, 39(12), 2913-2922.

Otani, A., Dorrell, M. I., Kinder, K., Moreno, S. K., Nusinowitz, S., Banin, E., Heckenlively, J., \& Friedlander, M. (2004) Rescue of retinal degeneration by intravitreally injected adult bone marrow-derived lineage-negative hematopoietic stem cells. Journal of Clinical Investigation, 114, 765-774.

Pagon, R. A. Retinitis pigmentosa (1988). Survey of Ophthalmology, 33, 137-177.

Pardue, M. T., Phillips, M. J., Yin, H., Sippy, B. D., Webb-Wood, S., Chow, A. Y., \& Ball, S. L. (2005). Neuroprotective effect of subretinal implants in the RCS rat. Investigative Ophthalmology \& Visual Science, 46, 674-682.

Peng, B., Xiao, J., Wang, K., So, K. F., Tipoe, G. L., \& Lin, B. (2014). Suppression of Microglial Activation Is Neuroprotective in a Mouse Model of Human Retinitis Pigmentosa. The Journal of Neuroscience, 34(24), 8139-8150.

Pescosolido, N., Barbato, A., Pascarella, A., Giannotti, R., Genzano, M., \& Nebbioso, M. (2014). Role of Protease-Inhibitors in Ocular Diseases. Molecules, 19(12), 20557-20569.
Pittenger, M. F., Mackay, A. M., Beck, S. C., Jaiswal, R. K., Douglas, R., Mosca, J. D., Moorman, A., Simonetti, D. W., Craig, S., \& Marshak, D. R. (1999). Multilineage potential of adult human mesenchymal stem cells. Science, 284, 143-7.

Punzo, C., Xiong, W., \& Cepko, C. L. Loss of Daylight Vision in Retinal Degeneration: Are Oxidative Stress and Metabolic Dysregulation to Blame? Journal of Biological Chemistry 287(3), 1642-8.

Qureshi, A. H., Chaoji, V., Maiguel, D. Faridi, M. H., Barth, C. J., Salem, S. M., Singhal, M., Stoub, D., Krastins, B., Ogihara, M., Zaki, M. J., \& Gupta, V. (2009). Proteomic and phosphoproteomic profile of human platelets in basal, resting state: insights into integrin signaling. PLoS One, 22(6),490-495.

Rajashekhar, G., Ramadan, A., Abburi, C., Callaghan, B., Traktuev, D. O., Evans-Molina, C., Maturi, R., Harris, A., Kern, T. S., \& March, K. L. (2014). Regenerative therapeutic potential of adipose stromal cells in early stage diabetic retinopathy. PLoS One, 9(1), e84671.

Romanov, Y. A., Darevskaya, A. N., Merzlikina, N. V., \& Buravkova, L. B. (2005). Mesenchymal Stem cells from Human Bone Marrow and Adipose Tissue: Isolation, Characterization, and Differentiation Potentialities. Cell Technologies in Biology and Medicine, 3, 158-163.

Sabel, B. A., Flammer, J., \& Merabet, L. B. (2018). Residual vision activation and the brain-eye-vascular triad: Dysregulation, plasticity and restoration in low vision and blindness - a review. Restorative Neurology and Neuroscience, 36(6), 767-791.

Sandberg, M. A., Brockhurst, R. J., Gaudio, A. R., \& Berson, E. L. (2005). The association between visual acuity and central retinal thickness in retinitis pigmentosa. Investigative Ophthalmology \& Visual Science, 46, 3349-3354.

Schatz, A., Arango-Gonzalez, B., Fischer, D., Enderle, H., Bolz, S., Rock, T., Naycheva, L., Grimm, C., Messias, A., Zrenner, E., Bartz-Schmidt, K. U., Willmann, G., \& Gekeler, F. (2012). Transcorneal electrical stimulation shows neuroprotective effects in retinas of light-exposed rats. Investigative Ophthalmology \& Visual Science, 53, 5552-5561.

Schaffler, A., \& Buchler, C. (2007). Concise review: adipose tissuederived stromal cells-basic and clinical implications for novel cell-based therapies. Stem Cells, 25, 818-882.

Schatz, A., Rock, T., Naycheva, L., Willmann, G., Wilhelm, B., Peters, T., Bartz-Schmidt, K. U., Zrenner, E., Messias, A., \& Gekeler, F. (2011). Transcorneal electrical stimulation for patients with retinitis pigmentosa: a prospective, randomized, sham-controlled exploratory study. Investigative Ophthalmology \& Visual Science, 52, 4485-4496.

Schmid, H., Herrmann, T., Kohler, K., \& Stett, A. (2009).Neuroprotective effect of transretinal electrical stimulation on neurons in the inner nuclear layer of the degenerated retina. Brain Research Bulletin, 79, 15-25.

Schmidt, K. U., Willmann, G., Gekeler, F. (2012). Transcorneal electrical stimulation shows neuroprotective effects in retinas of light-exposed rats. Investigative Ophthalmology \& Visual Science, 53, 5552-5561.

Shen, J., Yang, X., Dong, A., Petters, R. M., Peng, Y. W., Wong, F., \& Campochiaro, P. A. (2005). Oxidative damage is a potential cause of cone cell death in retinitis pigmentosa. Journal of Cellular Physiology, 203(3), 457-64. 
Siniscalco, D., Giordano, C., Galderisi, U., Luongo, L., Alessio, N., Di Bernardo, G., de Novellis, V., Rossi, F., \& Maione, S. (2010). Intra-brain microinjection of human mesenchymal stem cells decreases allodynia in neuropathic mice. Cellular and Molecular Life Sciences, 67, 655-69.

Takahashi, K., \& Yamanaka, S. (2013). Induced pluripotent stem cells in medicine and biology. Development, 140, 2457-2461.

Tamaki, M., \& Matsuo, T. (2011). Optical coherence tomographic parameters as objective signs for visual acuity in patients with retinitis pigmentosa, future candidates for retinal prostheses. Journal of Artificial Organs, 14, 140-150.

Tilg, H., \& Moschen, A. (2006). Adipocytokines: mediators linking adipose tissue, inflammation and immunity. Nature Reviews Immunology, 6, 772-783.

Tucker, B. A., Mullins, R. F., \& Stone, E. M. (2014). Stem cells for investigation and treatment of inherited retinal disease. Human Molecular Genetics, 23, R9-R16.

Ueki, Y., \& Reh, T. A. (2013). EGF stimulates Müller glial proliferation via a BMP-dependent mechanism. Glia, 61, 778-789.

Verboschi, F., Domanico, D., Nebbioso, M., Corradetti, G., Scalinci, S. Z., \& Vingolo, E. M. (2013). New trends in visual rehabilitation with MP-1 microperimeter biofeedback: optic neural dysfunction. Functional Neurology, 28(4), 285-91.

Wang, A. L., Lukas, T. J., Yuan, M., Du, N., Tso, M.O., \& Neufeld, A.H. (2009). Autophagy and exosomes in the aged retinal pigment epithelium: Possible relevance to drusen formation and age-related macular degeneration. PLoS One, 4(1), e4160.

Wang, P., Mariman, E., Renes, J., \& Keijer, J. (2008). The secretory function of adipocytes in the physiology of white adipose tissue. Journal of Cellular Physiology, 216, 3-13.
Witkin, A. J., Ko, T. H., Fujimoto, J. G., Chan, A., Drexler, W., Schuman, J. S., Reichel, E., \& Duker, J. S. (2006). Ultrahigh resolution optical coherence tomography assessment of photoreceptors in retinitis pigmentosa and related diseases. American Journal of Ophthalmology, 142, 945-952.

Yang, Y., Mohand-Said, S., Danan, A., Simonutti, M., Fontaine, V., Clerin, E., Picaud, S., Léveillard, T., \& Sahel, J. A. (2009). Functional cone rescue by RdCVF protein in a dominant model of retinitis pigmentosa. Molecular Therapy, 17(5), 78795.

Yang, Y., Peng, J., Ying, D., \& Peng, Q. H. (2018). A Brief Review on the Pathological Role of Decreased Blood Flow Affected in Retinitis Pigmentosa. Journal of Ophthalmology, 3249064.

Zarbin, M. (2016). Cell-based therapy for degenerative retinal disease. Trends in Molecular Medicine, 22, 115-34.

Zeiss, C. J., \& Johnson, E. A. (2004). Proliferation of microglia, but not photoreceptors, in the outer nuclear layer of the rd-1 mouse. Investigative Ophthalmology \& Visual Science, 45(3), 971-6.

Zeng, H. Y., Zhu, X. A., Zhang, C., Yang, L. P., Wu, L. M., \& Tso, M. O. M. (2005). Identification of sequential events and factors associated with microglial activation, migration, and cytotoxicity in retinal degeneration in rd mice. Investigative Ophthalmology \& Visual Science, 46(8), 2992-2999.

Zhou, W. T., Ni, Y. Q., Jin, Z. B., Zhang, M., Wu, J. H., Zhu, Y., Xu, G. Z., \& Gan, D. K. (2012). Electrical stimulation ameliorates light-induced photoreceptor degeneration in vitro via suppressing the proinflammatory effect of microglia and enhancing the neurotrophic potential of Muller cells. Experimental Neurology, 238, 192-208. 